\title{
An Examination of the Impact of Astroturfing on Nationalism: A Persuasion Knowledge Perspective
}

\author{
Kenneth M. Henrie ${ }^{1, *(1)}$ and Christian Gilde ${ }^{2}$ \\ 1 Stiller School of Business, Champlain College, Burlington, VT 05401, USA \\ 2 Department of Business and Technology, University of Montana Western, Dillon, MT 59725, USA; \\ Christian.gilde@umwestern.edu \\ * Correspondence: khenrie@champlain.edu; Tel.: +1-802-865-8446
}

Received: 7 December 2018; Accepted: 23 January 2019; Published: 28 January 2019

\begin{abstract}
One communication approach that lately has become more common is astroturfing, which has been more prominent since the proliferation of social media platforms. In this context, astroturfing is a fake grass-roots political campaign that aims to manipulate a certain audience. This exploratory research examined how effective astroturfing is in mitigating citizens' natural defenses against politically persuasive messages. An experimental method was used to examine the persuasiveness of social media messages related to coal energy in their ability to persuade citizens', and increase their level of nationalism. The results suggest that citizens are more likely to be persuaded by an astroturfed message than people who are exposed to a non-astroturfed message, regardless of their political leanings. However, the messages were not successful in altering an individual's nationalistic views at the moment of exposure. The authors discuss these findings and propose how in a long-term context, astroturfing is a dangerous addition to persuasive communication.
\end{abstract}

Keywords: astroturfing; persuasion knowledge; nationalism; coal energy; social media

\section{Introduction}

Astroturfing is the simulation of a political campaign which is intended to manipulate the target audience. Often, the purpose of such a campaign is not clearly recognizable because a political effort is disguised as a grassroots operation. This exploratory research took a closer look at the persuasive properties of astroturfing in the contexts of nationalism and the coal energy sector. The prevalent literature in this area points to concepts such as persuasion, nationalism, and energy, which were investigated in regard to this exploratory research. In the same vein, involvement as a subtopic was addressed. An exploratory experimental design tested social media messages related to coal energy in a nationalistic context. The affect-behavior-cognition model was utilized to realize the persuasion measures. Two experimental conditions simulated an astroturfed and non-astroturfed message. First results of this research suggested that people with and without nationalist tendencies are more likely to be persuaded by an astroturfed message than people who are exposed to non-astroturfed message. The following paper chronicles an examination into how persuasion may impact one's own nationalistic tendencies, how individuals react to persuasion attempts in a commercial context, and how the use of a relatively new political tool known as astroturfing might noticeably mitigate the effectiveness of an individual's coping mechanism. Overall, this research contributes to the areas of nationalism, synthetic campaigns, energy, and political manipulation.

\section{Astroturfing-A History}

Contemporary astroturfing emerged in the early 2000s with the rise of the millennial generation, the election of Barack Obama, the rise of social media, and the popularization of issues such as 
climate change and industrial deregulation. Especially loose industry regulations added fuel to this movement. Generally understood, astroturfing is comprised of "political actions masquerading as grassroots efforts" (Lee 2010, p. 73). However, the first inklings of astroturfing emerged in the early twentieth century. Around 1910, one of the early versions of an astroturfing-like campaign promoted drinking water from disposable paper cups rather than sharing cups. Some of the reasons that were cited for pushing this change were enveloped in a health and hygiene narrative. At the time, other campaigns were launched as well to reeducate consumers and redirect their behavior to switch to paper cups. However, the peculiarity of this entire effort was that the publisher of the campaign flyer The Cup-Campaigner was no other than Hugh Moore, a co-founder of the Public Vendor Company, which would later become the Dixie Cup Company (Lee 2010). In addition, Moore distributed materials with specific instructions on how to influence your local politicians to support this effort. These were the beginnings of the product-boycotting movement that supports specific causes; a tool that has become, nowadays, one of the most widely used approaches in American politics to encourage change (Lee 2010). This approach allowed, mostly, wealthy capitalists and corporate titans to further their interests with the help of the public.

This activism and initiatives proliferated at the turn of the twenty-first century, showing that consumer activism and corporate profitability can go hand-in-hand. In the same vein, these developments encouraged companies to sponsor progressive causes dear to consumers to benefit their own operations.

\subsection{The Evolution of Astroturfing}

The term astroturfing is derived from the word "astroturf", which is a brand of artificial grass that is supposed to look like real grass and is mostly used for athletic fields to play sports, such as tennis and soccer. McNutt (2010) uses this logic to define astroturfing organizations as fake entities which are simulated grassroots movements (Lyon and Maxwell 2004) which are created and supported by corporations to promote their views, claims, and products. One of the primary goals of astroturfing organizations is to promote business interests. Therefore, it does not come as a surprise that this tool is often used in the context of political activism (Krashinsky 2009; MacKenzie and Pickard 2009). The effects of these political activist campaigns can be the influencing of public opinion or discrediting of scientific research, to influence policy in the interest of advancing corporate agendas (Mattingly 2006).

Examples of astroturfing campaigns can be found in the tobacco industry (Apollonio and Bero 2007; Tsoukalas and Glantz 2003) to, for instance, discredit the effects of second-hand smoke or in the pharmaceutical industry to challenge animal rights groups that are against animal drug testing. In a more concrete astroturfing example, a grassroots campaign called People of the West! supports western communities and receives a lot of its funding from corporate sponsors, some of whom have a strong interest in keeping alive the General Mining Act of 1872-The Act allows corporations to purchase and mine public lands for \$5 per acre (Lyon and Maxwell 2004). In another tangible astroturfing example, IBM openly encouraged its employees to blog in favor of the company and against competitors (Cox et al. 2008). Mustafaraj and Metaxas (2010) found evidence of online astroturfing via Twitter during the Massachusetts senate race between Martha Coakley and Scott Brown.

As can been seen form the previous examples, astroturfing takes place when people are paid to represent certain beliefs for organizations or parties through various communication channels. At the heart of the astroturfing paradigm is the creation of a false message used to support a specific issue (Zhang et al. 2013). However, astroturfing has also spread to the Internet and is seen, in this context, as a coordinated campaign "where messages supporting a specific agenda are distributed via the Internet. These messages employ deception to create the appearance of being generated by an independent entity" (Zhang et al. 2013, p. 1). As with many aspects of communication, persuasion, and culture, astroturfing has evolved with the advent of social media. 


\subsection{Digital Astroturfing}

Today, a vast and ever-growing amount of information and data can be found on the Internet. World Wide Web and social media users who want to support a particular opinion or look for information on a specific subject will search, more likely than not, the Internet. Often, next to real knowledge, Web pages also present opinions of Internet users. In addition, since many private and public sources are viewed as incredible, consumers utilize alternative and (for them) trusted sources to get their information, such as social networks and online forums (Quandt 2012). In this respect, negative comments or poorly rated information will discourage consumers from using this information, while the opposite will be true for highly rated information (Chen and Xie 2008; Dellarocas et al. 2007; Senecal and Nantel 2004).

Sadly, some of these data could be false or manipulated and released by a hired source to spread a certain organizational message (Cho et al. 2011; Daniels 2009; Mackie 2009); in other words, online astroturfing is used. The advantages to use the online medium for astroturfing are low cost and relative anonymity of the source (Mackie 2009). Since it can be somewhat difficult to find the identity of an information source, the information source can easily disguise its true self (Stajano and Wilson 2011). A number of recent Internet publications were exposed as using automated astroturfing through Twitter (Chu et al. 2010).

Many of the aforementioned misleading online efforts can be referred to as digital astroturfing. Kovic et al. (2016) define digital astroturfing as "a form of manufactured, deceptive and strategic top-down activity on the Internet initiated by political actors that mimics bottom-up activity by autonomous individuals" (p. 4). This definition suggests that in order to avail of effective digital astroturfing, it might be good that five conditions are fulfilled; namely, astroturfing should be on the internet, politically initiated, manufactured, strategic, and deceptive (Kovic et al. 2016). The authors of this definition also make a distinction between traditional and digital astroturfing through the fact that different genuine grassroots components are part of regular astroturfing while digital astroturfing is more simply structured. The authors draw, with the aforementioned definition, digital astroturfing into the political arena. In this case, political actors compose bogus grassroots activities on the Internet. There are many different political messages online that pretend to be honest opinions of internet users, when, as a matter of fact, they are not and disguise their true nature. Leiser (2016) refers to this digital phenomenon as "CyberTurfing" and says that it digitally spreads false information in order to further political agendas and, thus, undermines trust and democratic dialog.

In summation, astroturfing can be found more and more in the digital realm and uses the benefits online media have to offer to its advantage. Little experimental research has been conducted at the individual level in the context of astroturfing campaigns (Cho et al. 2011). In addition, online astroturfing has not been investigated intensively by scholars (Zhang et al. 2013). However, when an astroturfing campaign is successful, it "creates falsified impressions among decision makers or the general public and achieves the goal of persuasion" (Zhang et al. 2013, p. 2).

\section{Nationalism}

The definition and analysis of nationalism has proven quite difficult over the years, despite the profound impact that it exerts on modern society (Anderson 1983) and has been largely neglected (Hutchinson and Smith 1994). The nature of identifying and categorizing nationalism as an ideology can be problematic, as a citizen objectively will have a nation, and a national identity by nature of their birth within, but their connection with said nation (e.g., community) is largely imagined. Anderson (1983) explains that within a nation, the concept of community is specious, as most fellow citizens will never know their peers and remain unaware of the existence of most of their nation's brethren. Gellner (1987) concurs with this notion, as citizens, "identify with the collectivity, without being acquainted with its other members" (p. 6). Anderson (1983) further argues that any sovereignty possessed by said nation is largely imagined, as nationalism has emerged in response to generations of monarchal and religious rule in Europe, largely justified by sovereignty. This is a logical evolution 
of a society given the assertion by Smith (1981), that nationalism's roots lie in ethnic identity and post-enlightenment historicism among secular individuals in search of a viable faith.

Gellner (1983) asserts that nationalism is a matter of political legitimacy, where there is a degree of congruency between the political and national units. Thus, nationalistic sentiments revolve around one's desire to fulfil this condition. A key condition of nationalism is that citizens serve as 'clerks', in that they possess sufficient literacy to create, "cultural and cognitive storage and centralization" (Gellner 1983, p. 9). Nationalism is not a natural construct, instead a clearly man-made phenomenon, as political boundaries expand far beyond small city-states. Gellner (1964) explains, "nationalism is not the awakening of nations to self-consciousness: it invents nations where they do not exist" (p. 168). However, regardless of its natural state, nationalism is real as it is supported and perpetuated by literacy, education, and the dissemination of homogeneous cultural values (Gellner 1987). In support of this notion, Miller (1995) explicates that nationalism relates more closely to one's own national identity than their specific political orientation. The implications of this assertion are twofold: One, that such identities are communicated and manifested culturally (as implied by Gellner 1987), and that the outcomes of nationalism can be culturally dependent (also concluded by Miller 1995).

Given this cultural variability of nationalistic outcomes, there is the possibility that nationalism and the identity and unity inspired by the construct may sometimes take on a distinct appearance and focus in certain cultures. Some researchers, particularly in the United States, have discovered that some perceive nationalism to relate to a view that one's own country is superior to other nations (Feshbach 1994; Kosterman and Feshbach 1989; Mummendey et al. 2001). Nationalism can be negatively correlated with internationalism (Kosterman and Feshbach 1989) and positively correlated with militarism (Furia 2002; Kosterman and Feshbach 1989) in certain contexts. Critics of nationalism do question its ability to maintain peace and stability in contrast with a more global view, devoid of national boundaries and ambitions (Miller 1995).

Given the complex nature of nationalism, it also manifests itself based upon some myriad factors, that develop over time. Individuals' nationalism is shaped by socialization from a number of forces (e.g., national rituals, media), and represents an aggregate of an individual's attitudes toward a nation (Dekker et al. 2003), most notably in terms of their beliefs, feelings, and behavior (Ajzen and Fishbein 1980). Charismatic individuals can have a profound impact on one's nationalism (Dekker et al. 2003), as can the use of language in post-colonial societies (Albaugh 2007). Clearly, one's own nationalism is a product of external influence by socialization, and persuasive mass media (Hutchinson and Smith 1994).

\section{Persuasion Knowledge}

The Persuasion Knowledge Model posits that persuasion episodes exist when consumers are in a position to recognize and react to a persuasion attempt initiated by an agent, such as a salesperson or advertisement (Friestad and Wright 1994). Most notably, consumers examine the tactics, motives, and appropriateness of the tactics utilized by the agent. Consumers utilizing persuasion knowledge will typically mitigate the efficacy of the persuasive message due to a triggering of skepticism (Kirmani and Zhu 2007), the attribution of negative motives to the agent (Henrie and Taylor 2009), and a general mistrust of the agent (Boush et al. 1994). Several antecedent forces influence the likelihood that persuasion knowledge is triggered, accessibility of motives and cognitive capacity (Campbell and Kirmani 2000). Cognitive capacity refers to the situation capacity of a consumer to observe and process stimuli. Accessible motives are those that are clearly manifested by observable behavior by the agent. Thus, the likelihood that a consumer utilizes persuasion knowledge is mitigated in distracting environments, or in situations where persuasion agents can successfully mask their motives (e.g., Campbell and Kirmani 2000; Henrie and Taylor 2009). Involvement is also a significant antecedent, as individuals with higher involvement (e.g., knowledge of, or personal interest in) in a subject are more likely to reject persuasive messages (Petty and Cacioppo 1990). 
Ultimately, the motive of consumers to expend the effort to utilize persuasion knowledge is to maintain control over persuasion outcomes (Friestad and Wright 1994) and resist the pressure often exerted by persuaders like salespeople (Zboja et al. 2015). The results of persuasion knowledge are not always negative, as agents that use tactics that are deemed as benevolent and consumer oriented (Henrie and Miller 2011), or credible (Issac and Grayson 2017) are viewed positively by consumers; thus, persuasion knowledge in these cases enhanced the efficacy of the persuasion episode. Regardless, of outcomes, the extant literature examines persuasion knowledge in a purely commercial context. Thus, little is known about a citizen's ability to, or interest in persuasion knowledge to defend themselves from deceptive political messages. Likewise, where the accessibility of motives may be greatly reduced through astroturfing, will consumers be capable of resisting the persuasive impact of these political messages at all? Therefore, the purpose of this study was to examine people's use of persuasion knowledge in a political context, specifically in its ability to mitigate the persuasive impact and effectiveness of astroturfing on nationalism. As indicated earlier, nationalism is subject at least in part by persuasive messages, and astroturfing is effective in masking the motives of a persuasive agent through the use of deception. The hypotheses of the study are as follows:

Hypothesis 1 (H1). Political messages that are astroturfed are more persuasive than others, as respondents are less likely to utilize persuasion knowledge to mitigate their effectiveness, regardless of political leaning.

Hypothesis 1a (H1a). Respondents with higher levels of political involvement are more likely to trigger persuasion knowledge regardless of experimental condition, and therefore are less likely to be persuaded by the political message.

Hypothesis 2 (H2). Political messages that are astroturfed are more likely to trigger higher instances of nationalism than others, as respondents are less likely to use persuasion knowledge to mitigate their effectiveness.

Following is a presentation of the methodology used to test the aforementioned hypotheses.

\section{Methodology}

The aim of this research was to examine the persuasive impact of digital astroturfing in an attempt to disseminate a political message. Coal was used as the political issue in questions, as it has been a frequent target of astroturfing efforts in the energy industry. Being the target of various media outlets, this issue has become a currently prevalent in politics in the United States. This is reflected in the definition of astroturfing used by Cho et al. (2011) which identifies astroturfing organizations as "fake grassroots organizations usually sponsored by large corporations to support any arguments or claims in their favor" (p. 571). In 2009, a webpage called "Faces of Coal" was promoting its inclusivity showing an alliance of people from different strata of the social spectrum (Lee 2010). However, the website really used images bought from Stockphoto.com and paid oil company employees to attend rallies supporting the energy industry. In addition, energy industry supporters where prepared with specific talking points to be repeated in online discussion forums.

Problems associated with the coal thematic are environmental issues, such as global warming, and economic issues, such as unemployment. Since one of the primary methods to generate energy in today's market are different carbon-based natural resources, this topic is very contested. In the case of global warming, the controversy stems from the argument that global warming is caused through the use of carbon-based energy and that common sense would suggest, in order to reduce the effects of coal, the consumption of carbon-based energy has to be reduced (Cho et al. 2011). This is contrary to industry thinking which supports an economy that is powered by carbon-based energy. In this context, agents that support the carbon economy are using astroturfing organizations in order to counter and discredit the global warming movement.

The energy lobby uses the advantages provided by astroturfing in order to disguise its true identity, prey on established beliefs of their target audience, and use confusing arguments (Cho et al. 2011). 
Outcomes of these efforts are increased uncertainty about the legitimacy of the global warming story and doubt about the validity of the cause of the global warming movement. Therefore, it is a politically relevant topic with more than one facet of controversy and relevance to the citizenry of the United States, and the source of numerous hostile debates.

After selecting coal as the target industry for the research, the sampling frame for the study was defined. The sampling frame consisted of social media users aged 18-40 in the United States. These individuals are of legal voting age, and among the most active participants of social media (Cohen 2017). The authors utilized a snowball sampling method, where respondents were identified, then asked to help recruit additional respondents using the viral nature of their social media accounts. Social networks can be very useful in informing how people interact and in the recruitment of respondents (Browne 2005). An online survey produced 209 usable responses.

To examine the ability of digital astroturfing to mitigate persuasion knowledge, a 2-condition experimental design was used similar to Campbell and Kirmani (2000) and Henrie and Taylor (2009). One condition represents the high accessibility of motives (traditional) while the other represents low accessibility, due to the use of astroturfing). In order to examine the extent to which astroturfing effects nationalism and persuades people through organizational messages shown on their websites or in their twitter accounts, an experiment was conducted using a two-by-two between-subjects design. The following paragraphs provide details about the sample design, experimental manipulations, statistical procedures, and measurement variables.

\subsection{Experimental Manipulations}

Respondents were randomly assigned to one of two conditions, one of an authentic Twitter message sponsored by the "American Coalition for Clean Coal Electricity" (ACCCE) discussing the reliability of coal as a source of electricity, indicating that it contributes positively to the stability of the US electric grid (Bloodworth 2018). This was identified as the traditional message, where astroturfing was not utilized in the persuasive message to mitigate accessibility of motives. Therefore, respondents should have been free to utilize persuasion knowledge.

The second condition was a Twitter message by an imaginary organization, "Americans for Responsible Energy Choices" (AREC) that shared a message critical of the economic sustainability of coal, and its ability to provide jobs in the United States. This is considered the astroturfing condition, as while it links to an authentic article, the message originates from a false grass roots organization, mitigating the accessibility of motives of the original persuasive agent. The astroturfing condition was developed after an extensive review of extant astroturfing tweets to ensure its ability to represent an example of the practice.

\subsection{Scales of Measurement}

The experimental procedures and variables were carefully selected. Participants were randomly assigned to one of the two conditions. A seven-point Likert scales anchored at $1=$ "strongly disagree", and 7 = "strongly agree" was used to measure the responses. The participants personal level of nationalism and involvement in the context of coal-energy were measured.

Nationalism was measured using 6 scale items from Kosterman and Feshbach (1989) as used in $\mathrm{Li}$ and Brewer (2004). The items used language, such as, "In view of America's moral and material superiority, it is only right that we should have the biggest say in deciding United Nations policy", "The first duty of every young American is to honor the national American history and heritage", "Other countries should try to make their government as much like ours as possible", "Foreign nations have done some very fine things but it takes America to do things in a big way", "It is really important that the U.S. be number one in whatever it does", and "People should support their country even if the country is in the wrong".

Involvement was measured using the scale developed by Strutton et al. (1995). These items were adapted to politics resulting in the following 7 point Likert scales: "I long for a simple life in which 
political decisions do not have to be made", "I find it difficult to imagine enthusiasm concerning politics", and "The attempt to understand politics is a waste of time".

Persuasion outcomes were measured using the 7 point scales utilized by Henrie and Miller (2011) to measure persuasive outcomes in a persuasion knowledge context. They resemble the ABC model of attitudes, reflected in Ajzen and Fishbein (1980) persuasive outcomes of nationalism including affect: "This tweet changed the way I feel about coal energy in the US" and "This tweet changed the way I feel about being American"; cognition: "This tweet changed the way I think about coal energy in the US", "This tweet changed the way I think about being American", "Coal energy is reliable", and "Coal industry jobs are sustainable"; and behavioral; "This tweet changed the way I would vote regarding coal energy in the US".

To analyze these data, independent sample $t$-tests were used to examine differences between groups as hypothesized in Hypotheses 1 and 2. ANCOVA was used to examine the influence of involvement as a co-variate as hypothesized in Hypothesis 1a.

\section{Results}

Data were analyzed using SPSS statistical software. Following are the results by hypotheses. The results for Hypotheses 1 and 1a can be found in Table 1. Results for Hypothesis 3 can be found in Table 2.

Hypothesis 1 was examined using an independent samples $t$-test (see Table 1), respondents in the astroturfing condition were significantly $(p<0.05)$ higher (Mean $=13.95)$ than those in the non-astroturfing condition (Mean $=10.20$ ). To measure for the confounding impact of political leaning, an ANCOVA was conducted using leaning $(1=$ conservative, $7=$ liberal $)$ as a covariate. The model was insignificant $(p=0.581)$, indicating that the astroturfing condition was more persuasive regardless of political ideology. Thus, $\mathrm{H} 1$ is supported.

To test hypothesis 1a, a subsequent ANCOVA, with involvement introduced as a covariate, was significant $(p<0.05)$, indicating once again that involvement plays a role in persuasion knowledge. Therefore, H1a is also supported.

Hypothesis 2 was examined using another independent samples $t$-test (see Table 2), there were no significant differences between experimental groups $(p=0.957)$. Therefore, $\mathrm{H} 2$ is not supported. However, it is interesting to note that the ANCOVA model becomes significant $(p<0.05)$ when political leaning is introduced as a covariate. Conservative respondents were far more likely to be nationalistic than liberal respondents, regardless of experimental condition. The authors believe that these statistical results have significant implications in terms of the role of social media as a potential influencer, and the policies that might be needed to regulate their impact on politics.

Following the presentation of the results is a discussion of the statistical outcomes as well as their possible policy implications, limitations, and future research opportunities.

Table 1. $t$-Test/ANCOVA Results for Hypothesis 1/1a.

\begin{tabular}{ccccccc}
\hline Persuasiveness & Condition & Mean & $\mathbf{F}$ & $\mathbf{t}$ & $\mathbf{d f}$ & Sig. (2 tailed) \\
\hline & Non Astrotufing Condition & 10.2037 & 24.106 & $(3.987)$ & 207 & 0.000 \\
Astroturfing Conditon & 13.95 & & & & \\
Political Leaning & & & 0.305 & & 1 & 0.581 \\
Involvement & & & 18.259 & & 1 & 0.000 \\
\hline
\end{tabular}

Table 2. $t$-Test/ANCOVA Results for Hypothesis 2.

\begin{tabular}{|c|c|c|c|c|c|c|}
\hline Nationalism & Condition & Mean & $\mathbf{F}$ & $\mathbf{t}$ & df & Sig. (2 tailed) \\
\hline & $\begin{array}{l}\text { Non Astrotufing Condition } \\
\text { Astroturfing Conditon }\end{array}$ & $\begin{array}{l}17.8148 \\
17.8713\end{array}$ & 1.827 & $(0.054)$ & 207 & 0.957 \\
\hline Political Leaning & & & 107.394 & & 1 & 0.000 \\
\hline
\end{tabular}




\section{Discussion}

The research issue posed in the beginning of this study focused on examining people's use of persuasion knowledge in a political context, specifically in its ability to mitigate the effectiveness of astroturfing, where the motives of the agent are clearly masked. In light of this examination, first results of the research support the authors' premise that astroturfing can be an effective tool of persuasion in when advancing political agendas. As evinced here, an imaginary organization was perceived as more persuasive in discussing a political issue than a well-established, authentic one. The implications of this are profound, in that the barriers to entry for creating digital astroturfed messages are remarkably low. Therefore, anyone with access to social media could begin to create and disseminate messages that appear to be a grassroots campaign, as opposed to the opinion of just one citizen. This is regardless of political leaning, indicating citizens are possible vulnerable regardless of their position on any given issue.

As discovered in past studies (e.g., Petty and Cacioppo 1990), the most significant defense mechanism in any persuasion episode is involvement. Respondents with a greater degree of political involvement were less likely to indicate an impact on attitudes as a result of exposure to the social media message. This is encouraging to some extent; however, one must consider that the citizens that are highly involved in political processes are not the only ones to vote on issues and for candidates.

In terms of nationalism, this particular interaction was not effective in changing one's own nationalistic perceptions. However, as indicated by Ajzen and Fishbein (1980), nationalism is a collection of attitudes over time, organized in a hierarchal structure (Dekker et al. 2003). So, whilst a single Twitter post may not have a profound impact of the overall construct of one's nationalism, it may certainly impact prerequisite attitudes that over time may result on fundamental changes in nationalism. Long-term exposure to astroturfed messages could have a profound impact on one's own nationalism over time.

Given these findings, the authors recommend a policy shift by social media companies. A pragmatic approach might be a concerted effort by social media platforms to identify and the sources of politically oriented messages utilizing their platform, similar to how they verify the authentic accounts that represent commercial interest (e.g., celebrities and corporations). By verifying the authenticity of the account holder these platforms would mitigate the impact of astroturfing, whose strength is in masking the true source of the message. Whilst this does nothing to improve the authenticity and accuracy of politically persuasive messages, overall, it could certainly address the sender's ability to imply that their efforts are supported by an imaginary grass roots campaign, improving the gravitas of the message. It is unlikely that astroturfing and other deceptive practices could ever be completely eliminated, but identifying authentic, well established grass roots organizations could mitigate the effectiveness of astroturfed message created by an imaginary origination. This is particularly important given the anonymity already provided by the internet. It can be remarkably difficult to identify the origin of messages, campaigns, and likewise the authenticity of the information disseminated via social media. Hence the proliferation of the 'fake news'.

\section{Limitations and Directions for Future Research}

As with many studies, this research was subject to some design limitations. The sample of the research was relatively small, therefore assigning the study an exploratory nature. The study focused on young adults ranging in age from 18 to 40, and examined only one social media channel as it relates to astroturfing, namely Twitter. The construct of persuasion knowledge was only applied in more general terms for this particular investigation.

Provided these aforementioned limitations, some opportunities for future expansions of this study arise. A bigger sample can be utilized by employing not only a snowball-like sampling approach but also including other sample venues such as blog-posts, news feeds, and applicable websites. Future research efforts can contribute further to the literature by looking at different genders and various demographics. Pursuing these future opportunities will allow researchers to more clearly understand 
how digital astroturfing influences certain demographics, the notion of nationalism and in a variety of political domains.

In conclusion, whilst the results suggest that astroturfing can certainly be persuasive in influencing one's position on a single political issue, astroturfing was not effective in influencing a respondent's nationalism. Political leanings were a far better predictor of nationalism in this study. However, this is one example of an astroturfed message using one social media tool, directed toward a relatively young audience of social media users. It might be possible that many small interactions over time, or the development of a campaign utilizing multiple social media platforms, could more effectively influence one's own nationalistic views. Persuasion is, after all, a cumulative process where persuasion targets evolve over time (Friestad and Wright 1994).

Author Contributions: Conceptualization, K.M.H. and C.G.; methodology, K.M.H. and C.G.; formal analysis, K.M.H.; writing—original draft preparation, K.M.H. and C.G.; writing—review and editing, K.M.H. and C.G.

Funding: This research received no external funding.

Acknowledgments: The authors wish to acknowledge the reviewers for their thoughtful feedback.

Conflicts of Interest: The authors declare no conflict of interest.

\section{References}

Anderson, Benedict. 1983. Imagined Communities. London: Verso.

Apollonio, Dorie E., and Lisa A. Bero. 2007. The Creation of Industry Front Groups: The Tobacco Industry and "Get Government Off Our Back". American Journal of Public Health 97: 419-27. [CrossRef]

Ajzen, Icek, and Martin Fishbein. 1980. Understanding Attitudes and Predicting Social Behavior. Englewood Cliffs: Prentice-Hall.

Albaugh, Ericka A. 2007. Language Choicein Education: A Politics of Persuasion. The Journal of Modern Africa Studies 45: 1-32. [CrossRef]

Bloodworth, Michelle. 2018. ACCCE Supports Senate Introduction of the "Electricity Reliability and Fuel Security Act". Available online: http:/ / bit.ly/2HsLiiV (accessed on 29 November 2018).

Boush, David M., Marian Friestad, and Gregory M. Rose. 1994. Adolescent Skepticism toward TV Advertising and Knowledge of Advertiser Tactics. Journal of Consumer Research 21: 165-75. [CrossRef]

Browne, Kath. 2005. Snowball sampling: Using social networks to research non-heterosexual women. International Journal of Social Research Methodology 8: 47-60. [CrossRef]

Campbell, Margaret C., and Amna Kirmani. 2000. Consumers' Use of Persuasion Knowledge: The Effects of Accessibility and Cognitive Capacity on Perceptions of an Influence Agent. Journal of Consumer Research 27: 69-83. [CrossRef]

Chen, Yubo, and Jinhong Xie. 2008. Online Consumer Review: Word of Mouth as a New Element of Marketing Communication. Management Science 54: 477-91. [CrossRef]

Cho, Charles H., Martin L. Martens, Hakkyun Kim, and Michelle Rodrigue. 2011. Astroturfing Global Warming: It Isn't Always Greener on the Other Side of the Fence. Journal of Business Ethics 104: 571-87. [CrossRef]

Chu, Zi, Steven Gianvecchio, Haining Wang, and Sushil Jajodia. 2010. Who is tweeting on twitter: Human, bot, or cyborg? Paper presented at ACM 26th Annual Computer Security Applications Conference, Austin, TX, USA, December 6-10.

Cohen, David. 2017. 86\% of U.S. Adults Aged 18-29 Are Social Media Users (Report). Adweek, January 12.

Cox, Joshua L., Eric R. Martinez, and Kevin B. Quinlan. 2008. Blogs and the Corporation: Managing the risk, reaping the benefits. The Journal of Business Strategy 29: 4-12. [CrossRef]

Daniels, Jessie. 2009. Cloaked websites: Propaganda, cyber-racism and epistemology in the digital era. New Media $\mathcal{E}$ Society 11: 659-83. [CrossRef]

Dekker, Henk, Darina Malová, and Sander Hoogendoorn. 2003. Nationalism and its Explanations. Political Psychology 24: 345-76. [CrossRef]

Dellarocas, Chrisanthios, Michael Zhang, and Neveen Awad. 2007. Exploring the value of online product reviews in forecasting sales: The case of motion pictures. Journal of Interactive Marketing 21: 23-45. [CrossRef] 
Friestad, Marian, and Peter Wright. 1994. The Persuasion Knowledge Model: How People Cope with Persuasion Attempts. Journal of Consumer Research 2: 1-31. [CrossRef]

Feshbach, Seymour. 1994. Nationalism, patriotism and aggression: A clarification of functional differences. In Aggressive Behavior: Clinical Perspectives. Edited by L. Rowell Huesmann. New York: Putnam, pp. 275-91. ISBN 0306445530.

Furia, Peter. 2002. Patriotism, nationalism, and international politics. Paper presented at Annual Meeting of the American Political Science Association, Boston, MA, USA, August 28.

Gellner, Ernest. 1964. Thought and Change. London: Weidenfield and Nicolson.

Gellner, Ernest. 1983. Nations and Nationalism. Oxford: Basil Blackwater.

Gellner, Ernest. 1987. Culture, Identity, and Politics. Cambridge: Cambridge University Press.

Henrie, Kenneth M., and Christopher Taylor. 2009. Use of persuasion knowledge by the millennial generation. Young Consumers 10: 71-81. [CrossRef]

Henrie, Kenneth M., and Darryl Miller. 2011. An Examination of Mediation: Insights into the Role of Psychological Mediators in the use of Persuasion Knowledge. International Journal of Consumer Relationship Marketing $\mathcal{E}$ Management 2: 16-27. [CrossRef]

Hutchinson, John, and Anthony D. Smith. 1994. Nationalism. Oxford: Oxford University Press.

Issac, Matthew, and Kent Grayson. 2017. Beyond Skepticism: Can Accessing Persuasion Knowledge Bolster Credibility? Journal of Consumer Research 43: 895-912. [CrossRef]

Kirmani, Amna, and Rui Zhu. 2007. Vigilant Against Manipulation: The Effect of Regulatory Focus on the Use of Persuasion Knowledge. Journal of Marketing Research 44: 688-701. [CrossRef]

Kosterman, Rick, and Seymour Feshbach. 1989. Toward a measure of patriotic and nationalistic attitudes. Political Psychology 10: 257-74. [CrossRef]

Kovic, Marko, Adrian Rauchfleisch, Marc Sele, and Christian Caspar. 2016. Digital Astroturfing in Politics: Definition, Typology, and Countermeasures. Stud. Commun. Sci. 18: 69-85. [CrossRef]

Krashinsky, Susan. 2009. Spread of astroturfing; bogus online reviews a growing problem, New York Attorney-General says. The Globe and Mail, July 17.

Lee, Caroline W. 2010. The Roots of Astroturfing. Contexts 9: 73-75. [CrossRef]

Leiser, Mark. 2016. AstroTurfing, 'CyberTurfing' and Other Online Persuasion Campaigns. European Journal of Law and Technology 7: 1-27.

Li, Qiong, and Marilynn B. Brewer. 2004. What Does It Mean to Be an American? Patriotism, Nationalism, and American Identity After 9/11. Political Psychology 25: 727-39. [CrossRef]

Lyon, Thomas P., and John W. Maxwell. 2004. Astroturf: Interest Group Lobbying and Corporate Strategy. Journal of Economics \& Management Strategy 13: 561-97. [CrossRef]

MacKenzie, Kate, and Jim Pickard. 2009. US oil industry split as leaked memo reveals lobbying plan. Financial Times, August 15.

Mackie, Gerry. 2009. Astroturfing Infotopia. Theoria: A Journal of Social E Political Theory 56: 30-56. [CrossRef]

Mattingly, James E. 2006. Radar Screens, Astroturf, and Dirty Work: A Qualitative Exploration of Structure and Process in Corporate Political Action. Business and Society Review 111: 193-221. [CrossRef]

McNutt, John G. 2010. Researching advocacy groups: Internet sources for research about public interest groups and social movement organizations. Journal of Policy Practice 9: 308-312. [CrossRef]

Miller, David. 1995. On Nationality. Oxford: Oxford University Press.

Mummendey, Amélie, Andreas Klink, and Rupert Brown. 2001. Nationalism and patriotism: National Identification and Outgroup Rejection. British Journal of Social Psychology 40: 159-72. [CrossRef]

Mustafaraj, Eni, and Panqagiotis Metaxas. 2010. From Obscurity to Prominence in Minutes: Political Speech and Real-Time Search. Paper presented at Web Science Conference, Raleigh, NC, USA, April 26-27.

Petty, Richard E., and John T. Cacioppo. 1990. Involvement and Persuasion: Tradition Versus Integration. Psychological Bulletin 107: 367-74. [CrossRef]

Quandt, Thorsten. 2012. What's Left of Trust in a Network Society? An Evolutionary Model and Critical Discussion of Trust and Societal Communication. European Journal of Communication 27: 7-21. [CrossRef]

Senecal, Sylvian, and Jacques Nantel. 2004. The Influence of Online Product Recommendations on Consumers' Online Choices. Journal of Retailing 80: 159-69. [CrossRef]

Stajano, Frank, and Paul Wilson. 2011. Understanding scam victims: Seven principles for systems security. Communications of the ACM 54: 70-75. [CrossRef] 
Smith, Anthony D. 1981. The Ethnic Revival. Cambridge: Cambridge Press.

Strutton, David, James R. Lumpkin, and Lou E. Pelton. 1995. Personality characteristics and salespeople's choice of coping strategies. Journal of the Academy of Marketing Science 23: 132-40. [CrossRef]

Tsoukalas, Theodore, and Stanton A. Glantz. 2003. The Duluth Clean Indoor Air Ordinance: Problems and Success in Fighting the Tobacco Industry at the Local Level in the 21st Century. American Journal of Public Health 98: 1214-21. [CrossRef]

Zboja, Jim, Ronald Clark, and Diana Haytko. 2015. An Offer You Can't Refuse: Consumer Perceptions of Sales Pressure. Journal of the Academy of Marketing Science 44: 806-21. [CrossRef]

Zhang, Jerry, Darrell Carpenter, and Myun Ko. 2013. Online Astroturfing: A Theoretical Perspective. Paper presented at Nineteenth Americas Conference on Information Systems, Chicago, IL, USA, August 15-17.

2019 by the authors. Licensee MDPI, Basel, Switzerland. This article is an open access article distributed under the terms and conditions of the Creative Commons Attribution (CC BY) license (http:/ / creativecommons.org/licenses/by/4.0/). 